\title{
ASSOCIATION OF SERUM ADIPONECTIN LEVELS WITH METABOLIC SYNDROME RISK FACTORS IN MALAY ADULTS
}

\author{
Nur Firdaus Isa ${ }^{1,3}$, Laila Ruwaida Mohd Zainuddin ${ }^{2}$, Wan Manan Wan Muda ${ }^{3}$, Hamid Jan B. \\ Jan Mohamed ${ }^{3}$ \\ 1 Department of Biotechnology, Kulliyyah of Science, IIUM, Kuantan, Pahang, Malaysia. \\ 2 School of Nutrition and Dietetics, Faculty of Health Sciences, Universiti Sultan Zainal Abidin (UniSZA), \\ Gong Badak Campus, 21300 Kuala Terengganu, Terengganu, Malaysia. \\ 3 Nutrition and Dietetics Programme, School of Health Sciences, Universiti Sains Malaysia, 16150 Kubang \\ Kerian, Kelantan, Malaysia
}

Abstract- Introduction: This study aimed to investigate the relationship between serum adiponectin and metabolic syndrome in adults living in rural Malaysia.

Methods: A total of 299 Malay adults (men=124; women $=175)$ with a mean age $48.8(11.7)$ years were recruited. Measurements for waist circumference and blood pressure were taken before drawing an overnight fasting blood samples. Biochemical tests for triglycerides, HDL cholesterol, glucose and serum adiponectin concentration were measured.

Results: Our results show that the adiponectin level in the subjects with metabolic syndrome was significantly lower than those without metabolic syndrome $(p<0.05)$. Among the metabolic syndrome risk factors, adiponectin level was significantly associated with hypertriglyceridemia and reduced HDL cholesterol $(p<0.001)$.

Conclusion: The outcome from this study which highlights the association of hypoadiponectinemia with risk factors of metabolic syndrome in Malay adults, suggests that the reduced level of adiponectin may play a pivotal role in the development of metabolic syndrome in this ethnic group.

Keywords: adipokines, metabolic syndrome, obesity, dyslipidaemia, Asian

\section{INTRODUCTION}

Metabolic syndrome is an emerging public health concern worldwide. The risk factors of metabolic syndrome are central obesity, hypertriglyceridaemia, reduced high-density lipoprotein cholesterol (HDL cholesterol), hypertension, and hyperglycemia. ${ }^{1}$ Based on the International Diabetes Federation (IDF) definition, the presence of central obesity with any two of the other risk factors is qualified for the diagnosis of metabolic syndrome. ${ }^{2}$

A comprehensive overview on metabolic syndrome pandemic in the America, Europe and India indicates that more than $20 \%$ of the adult populations have metabolic syndrome. ${ }^{1}$ Several South East Asian countries such as Indonesia, Singapore and Thailand are actively involved in evaluating the metabolic syndrome. ${ }^{3-7}$ There is growing interest in assessing whether metabolic syndrome is a health threat in our population. This is based on the accumulating reports documenting the occurrence of metabolic syndrome in Malaysia in various locations and sociodemographic background. ${ }^{8-11}$ Since the metabolic syndrome pandemic is observed in diverse population therefore there is a pressing need to investigate the mechanism underlying metabolic syndrome as well as searching for robust and sensitive biomarkers to serve as a diagnostic tool for early detection of metabolic syndrome.

The underlying mechanisms for development of metabolic syndrome remain plausible. The accumulated evidence suggests that the reduced adiponectin concentration (hypoadiponectinemia) plays pathophysiologic role of metabolic syndrome. The inverse correlation between visceral adiposity and adiponectin concentration suggests that hypoadiponectinemia is unequivocally associated with central obesity, a principal feature for metabolic syndrome. ${ }^{12-14}$

Adiponectin, a type of adipose-specific serum protein can be found extensively in serum ranging from $1.9-17.0 \mu \mathrm{g} / \mathrm{ml} .^{15}$ It is expressed inversely to total fat, and acted not only as antidiabetic but also as anti-inflammatory and anti-atherogenic agent. ${ }^{16}$ In the last few years, a growing body of evidence suggests that adiponectin is a potential biomarker for the metabolic syndrome 
and its risk factors. The present study was designed to examine the association between serum adiponectin level and metabolic syndrome or risk factors in the Malay adults in Malaysia.

\section{METHODS}

\section{Study subjects}

This was a cross-sectional study involving a total of 299 Malay adults recruited from October 2008 to August 2009. This study was approved by the Human Research Ethics Committee of Universiti Sains Malaysia (USMKK/PPP/JEPeM [205.4.(1.3)]. Written informed consent was obtained from all of the subjects. Each subject was interviewed using a structured questionnaire on demographic characteristics such as age, sex, and personal medical history. A qualified nutritionist measured height, weight and waist circumference using a portable bodymeter (Seca 206, Germany), body composition monitor (Tanita BC545, Japan) and non-elastic measurement tape (Seca 201, Japan). After 15 minutes of rest, blood pressure was measured twice by a trained laboratory technician using an automatic blood pressure monitor (Omron SEM-1, Japan). The general characteristics of the subjects were previously described. ${ }^{8}$

\section{Biochemical Tests}

Peripheral venous blood samples were collected after an overnight fasting. Metabolic syndrome biomarkers such as fasting blood glucose, triglycerides and high-density lipoprotein cholesterol were assessed with commercially available reagents (Randox, UK) by using Vitalab Selectra E chemistry analyzer (Vitalab, Netherlands). Serum adiponectin concentration was determined by using the Human Adiponectin Enzyme-Linked Immunosorbent Assay (ELISA) kit (Chemicon, USA).

\section{Definition of Metabolic Syndrome}

The following risk factors and criteria were used: central obesity (waist circumference; men $\geq 90 \mathrm{~cm}$, women $\geq 80 \mathrm{~cm}$ ) plus any two of the following: (1) raised triglycerides $(>1.7 \mathrm{mmol} / \mathrm{L}(150 \mathrm{mg} / \mathrm{dL})$ or specific treatment for this lipid abnormality); (2) reduced HDL-cholesterol (men $<1.03 \mathrm{mmol} / \mathrm{L}$ (40 $\mathrm{mg} / \mathrm{dL})$ or women $<1.29 \mathrm{mmol} / \mathrm{L}(50 \mathrm{mg} / \mathrm{dL})$ or specific treatment for this lipid abnormality); (3) raised blood pressure $(\geq 130 / 85 \mathrm{~mm} \mathrm{Hg}$ or treatment of previously diagnosed hypertension); (4) raised fasting plasma glucose $(\geq 5.6 \mathrm{mmol} / \mathrm{L}$ $(100 \mathrm{mg} / \mathrm{dL})$ or previously diagnosed type 2 diabetes).

\section{Statistical analyses}

Subjects with missing information in socioeconomic, anthropometric measurements and blood analyses were excluded from statistical analyses. Each variable was examined for normality of frequency distribution based on the histogram. Normally distributed data were expressed as mean (standard deviation or SD) and skewed data were expressed as median (Interquartile Range or IqR). The Mann-Whitney $U$ test was conducted to study association of adiponectin concentration and metabolic syndrome or risk factors. The two-way ANOVA analysis of variance was applied to explore the mean differences of adiponectin concentration on status of metabolic syndrome or risk factors. Although this test requires the dependant variables to be normally distributed, however it is robust against violations of the assumption of the normal distribution (17). A 2tailed value of $p<0.05$ was considered significant. All statistical analyses were performed using the Predictive Analytics Software (PASW Statistics 18.0) (SPSS Inc., Chicago, IL, USA).

\section{RESULTS}

A total of 299 Malay adults mean (Mean age \pm SD: $48.8 \pm 11.7)$ of which 124 were men $(49.8 \pm 11.7)$ and 175 were women $(48.6 \pm 11.8)$ were recruited in this study. Clinical characteristics of metabolic syndrome among the subjects i.e the mean (SD) for waist circumference, systolic and diastolic blood pressures, glucose, triglycerides and HDL cholesterol, and median (IqR) for adiponectin concentration are presented in Table 1. 
Table 1. General characteristics of the study subjects $(n=299)$

\begin{tabular}{llc}
\hline Characteristics & Mean & SD \\
\hline Age (years) & 48.8 & 11.7 \\
Waist Circumference (cm) & 83.8 & 11.3 \\
Systolic Blood Pressure (mmHg) & 134.8 & 23.1 \\
Diastolic Blood Pressure (mmHg) & 79.1 & 11.2 \\
Glucose (mmol/L) & 5.7 & 2.3 \\
Triglycerides $(\mathrm{mmol} / \mathrm{L})$ & 1.4 & 0.9 \\
HDL cholesterol $(\mathrm{mmol} / \mathrm{L})$ & 1.2 & 0.3 \\
& Median & IqR \\
Adiponectin $(\mu \mathrm{g} / \mathrm{ml})$ & 6.5 & 5.7 \\
\hline
\end{tabular}

The association of adiponectin level with metabolic syndrome were examined using Mann-Whitney $U$ test (Figure 1). The median (IqR) of adiponectin concentration among those with and without metabolic syndrome were $5.8(3.7) \mu \mathrm{g} / \mathrm{ml}$ and 7.2 (6.8) $\mu \mathrm{g} / \mathrm{ml}$, respectively. The adiponectin level among those with metabolic syndrome was significantly lower than those without metabolic syndrome $(p=0.004)$.
Subjects with high level of triglyceride (5.2 $\mu \mathrm{g} / \mathrm{ml}$ ) had significantly lower level of serum adiponectin than subjects with lower triglycerides $(7.7 \mu \mathrm{g} / \mathrm{ml})(p<0.001)$.

Similarly, subjects with reduced HDL cholesterol $(5.8 \mu \mathrm{g} / \mathrm{ml})$ had significantly lower concentration of serum adiponectin concentration than subjects with elevated HDL cholesterol $(8.1 \mu \mathrm{g} / \mathrm{ml})(p<0.001)$.

\section{DISCUSSION}

The total serum adiponectin level observed in the Malay population is comparable with a study conducted among the Japanese, but lower than in other populations (Table 3). The adiponectin concentration reported among the Malays with metabolic syndrome was significantly lower than those without metabolic syndrome; this finding is in agreement with other reported studies. ${ }^{18,19}$

The Malay subjects with hypertriglyceridemia or reduced HDL cholesterol had significantly lower concentration of serum

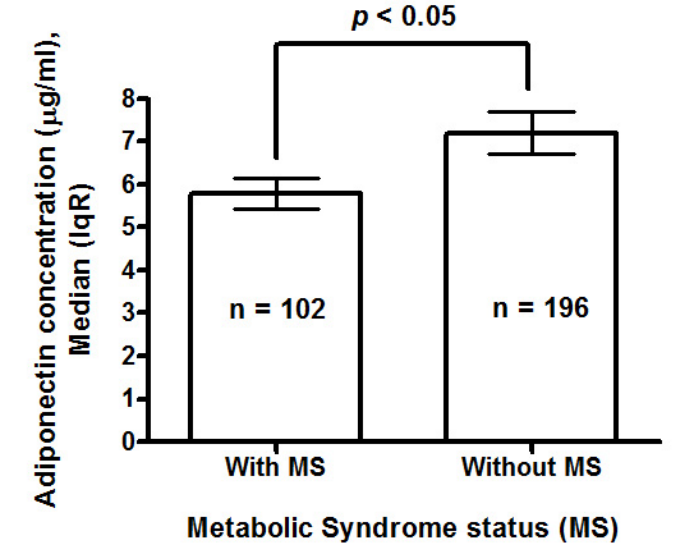

Figure 1. The median (IqR) of adiponectin concentration among subjects with and without metabolic syndrome (Mann-Whitney $U$ test)

The association of adiponectin concentration with adiponectin concentration than those without them, the individual metabolic syndrome risk factors is respectively. The result is in accordance with presented in Figure 2 and Table 2. previous reports from various population such as

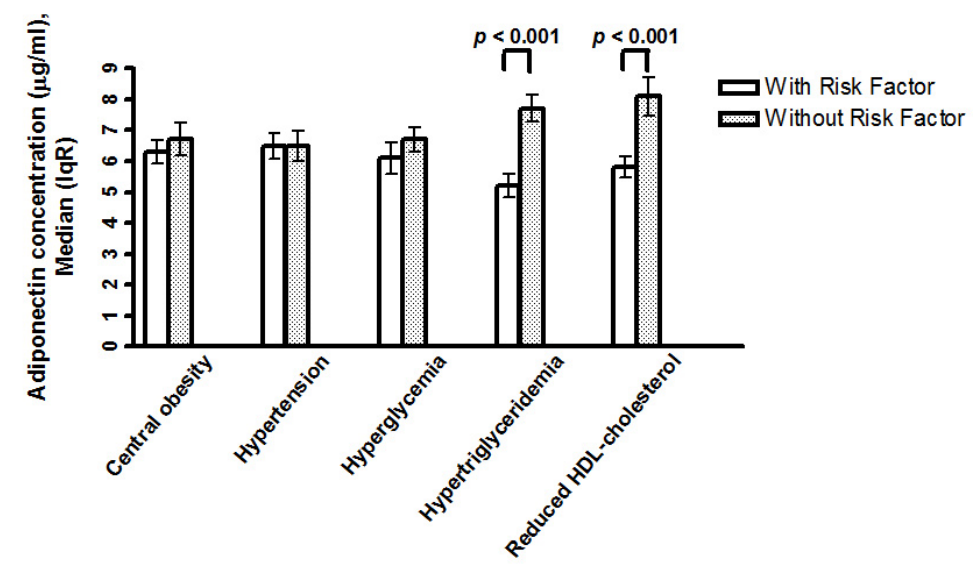


Table 2. The association between metabolic syndrome risk factors with the adiponectin concentration

\begin{tabular}{|c|c|c|c|c|c|}
\hline Risk Factors & Status & n (\%) & $\begin{array}{c}\text { Adiponectin } \\
(\mu g / \mathbf{m l}) \\
\text { Median (IqR) }\end{array}$ & Z-stat ${ }^{\mathbf{a}}$ & $p$-value \\
\hline \multirow{2}{*}{ Central obesity } & With & $146(48.7)$ & $6.3(4.6)$ & \multirow{2}{*}{-0.931} & \multirow{2}{*}{0.352} \\
\hline & Without & $153(51.3)$ & $6.7(6.6)$ & & \\
\hline \multirow{2}{*}{ Hypertension } & With & $168(56.0)$ & $6.5(5.4)$ & \multirow{2}{*}{-0.731} & \multirow{2}{*}{0.465} \\
\hline & Without & $131(44.0)$ & $6.5(5.6)$ & & \\
\hline \multirow{2}{*}{ Hyperglycemia } & With & $98(31.2)$ & $6.1(4.9)$ & \multirow{2}{*}{-1.157} & \multirow{2}{*}{0.247} \\
\hline & Without & $205(68.8)$ & $6.7(5.8)$ & & \\
\hline \multirow{2}{*}{ Hypertriglyceridemia } & With & $87(28.9)$ & $5.2(3.4)$ & \multirow{2}{*}{-5.488} & \multirow{2}{*}{$<0.001$} \\
\hline & Without & $212(71.1)$ & $7.7(6.4)$ & & \\
\hline \multirow{2}{*}{ Reduced HDL cholesterol } & With & $196(65.4)$ & $5.8(4.6)$ & \multirow{2}{*}{-3.215} & \multirow{2}{*}{$<0.001$} \\
\hline & Without & $103(34.6)$ & $8.1(6.3)$ & & \\
\hline
\end{tabular}

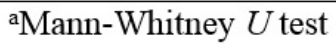

Caucasian $^{24}$ and Japanese $^{25}$ and large-scale nationwide studies such as Rancho Bernardo Study $^{26}$ and KORA Survey 2000. ${ }^{27}$ Although the exact crosslink between adiponectin and lipid metabolism remains unknown, it was proposed that adiponectin acts with HDL cholesterol in reverse

hexamers, medium molecular weight (MMW) and high molecular weight (HMW) multimerics. The HMW is thought to be the active form of the adiponectin, and is implicated in the progression of metabolic syndrome. ${ }^{30,31}$ Lara-Castro and the group reported that the reduced concentration of HMW

Table 3. Adiponectin concentration of Malay population and other populations

\begin{tabular}{lccc}
\hline \multicolumn{1}{c}{ Population } & Scope of the Study & Study Subjects & $\begin{array}{c}\text { Adiponectin } \\
\text { Concentration } \\
(\boldsymbol{\mu g} / \mathbf{m l})\end{array}$ \\
\hline Malays $^{\text {This study }}$ & Metabolic Syndrome & Men and Women & 6.5 \\
Indonesian $^{[7]}$ & Metabolic Syndrome & Men & 3.1 \\
Japanese $^{(20)}$ & Healthy Young Adults & Men & 6.4 \\
Non-Hispanic $_{\text {White }}^{(21)}$ & Pre-menopausal & Women & 12.4 \\
Hispanic $^{(21)}$ & Pre-menopausal & Women & 9.5 \\
Taiwanese $^{(22)}$ & Hyperglycemia & Men and Women & 7.8 \\
African $_{\text {Americans }}{ }^{(23)}$ & Insulin Resistance & Men & 12.9 \\
\hline
\end{tabular}

cholesterol transport and involved in hepatic lipase activity. ${ }^{28}$ The finding from this study whereby hypoadiponectinemia is significantly associated with hypertriglyceridemia and reduced HDL cholesterol, suggests that an increased in adiponectin level could have protective effect via promoting HDL cholesterol and reducing the triglycerides.

We found no significant association between adiponectin with central obesity which appears to be in contradiction with the previous reports. ${ }^{24,29}$ Such conflicting finding could be attributed by the adiponectin multimeric forms. Serum adiponectin exists as a trimer; low molecular weight (LMW) adiponectin was associated with measures of central fat distribution, rather than the total adiponectin that were commonly investigated by many researchers. ${ }^{32}$ As findings from this study found no significant association between adiponectin and central obesity, it was proposed that adiponectin, specifically the total adiponectin measured during the course of the study, was not responsible for the association with central obesity in Malay population. Perhaps future investigation of HMW would provide more conclusive perspective.

Circulating adiponectin levels have been studied for their role in different ethnic groups which suggests that adipose tissue mass or 
distribution may be attributed by ethnic variation. ${ }^{33}$ Since the present study displayed no significant association between adiponectin and central obesity, further studies on the influence of Malay ethnic factor perhaps could explain the discrepancy.

The adiponectin concentration found in Malay subjects with hypertension was similar to those without hypertension. To our knowledge there are limited studies associating adiponectin and hypertension as compared to other risk factors. Besides, a number of studies purposely examined hypoadiponectinemia and hypertension in selected patients with other abnormalities for example in patients with essential hypertension; a form of high blood pressure with no identifiable cause or among obese participant. $^{34,35}$

The association of hypoadiponectinemia and type 2 diabetes has been demonstrated as early as $2000 .^{36}$ Adiponectin is regarded as an insulin sensitizer that enhances insulin sensitivity by increasing fatty acid oxidation and inhibiting the hepatic glucose production. ${ }^{37}$ Several studies carried out in diverse population show that diabetic subjects experience hypoadiponectinemia as compared to their nondiabetic counterparts. ${ }^{38-40} \mathrm{We}$ found no significant difference of the adiponectin level between hyperglycemic and non-hyperglycemic in our studied subjects. Increasing the sample size and expanding this cross-sectional study to a cohort study with longer follow-up may fill in the gaps.

Here we report the association of adiponectin levels in the Malay ethnics in Malaysia and its association with metabolic syndrome risk factors. The study population was selected from a rural area, thus the result may not be generalised to Malays living in urban Malaysia due to differences in socioeconomic status. A nationwide multicentre study involving not only Malay ethnics but also Indian Malaysian and Chinese Malaysian may provide perspective into the role of adiponectin in the development of metabolic syndrome in Malaysian. Studies have suggested that adiponectin can be a promising therapeutic agent for metabolic syndrome and its risk factors. Increasing circulating adiponectin concentration or enhancing adiponectin signalling through its receptors could promisingly tackle the root that cause the metabolic syndrome. ${ }^{41}$ Although the claims excited many researchers, future investigations taking the ethnic differences into account, are required to support the matter.

\section{Conflicts of Interest}

The authors declare there is no conflict of interest regarding this research

\section{Acknowledgment}

We would like to thank Universiti Sains Malaysia Research University Grant Scheme for helping and funding this research.

\section{REFERENCES}

1. Grundy SM. Metabolic syndrome pandemic. Arterioscler Thromb Vasc Biol 2008;28(4):629-36.

2. Alberti KG, Zimmet P, Shaw J. Metabolic syndrome-a new world-wide definition. A Consensus Statement from the International Diabetes Federation. Diabet Med 2006;23(5):46980.

3. Lee J, Heng D, Ma S, Chew SK, Hughes K, Tai ES. The metabolic syndrome and mortality: the Singapore Cardiovascular Cohort Study. Clin Endocrinol 2008;69(2):22530 .

4. Aekplakorn W, Chongsuvivatwong V, Tatsanavivat P, Suriyawongpaisal P. Prevalence of metabolic syndrome defined by the International Diabetes Federation and National Cholesterol Education Program criteria among Thai adults. Asia Pac J Public Health 2011;23(5):792-800.

5. Soewondo P, Purnamasari D, Oemardi M, Waspadji S, Soegondo S. Prevalence of metabolic syndrome using NCEP/ATP III criteria in Jakarta, Indonesia: the Jakarta primary non-communicable disease risk factors surveillance 2006. Acta Med Indones 2010;42(4):199-203.

6. Kamso S. Prevalence of metabolic syndrome in older Indonesians. Asia Pac J Public Health 2008;20 Suppl:244-50.

7. Sartika CR, Lukito W, Wijaya A. Adiponectin, total anti-oxidant status, and high sensitivity C-reactive protein in Indonesian men with metabolic syndrome. Medical Journal of Indonesia 2009;18(4):262-8.

8. Zainuddin LR, Isa N, Muda WM, Mohamed HJ. The prevalence of metabolic syndrome according to various definitions and hypertriglyceridemic-waist in malaysian adults. Int J Prev Med 2011;2(4):229-37.

9. Rampal S, Mahadeva S, Guallar E, Bulgiba A, Mohamed R, Rahmat $R$, et al. Ethnic differences in the prevalence of metabolic syndrome: results from a multi-ethnic populationbased survey in Malaysia. PLoS One 2012;7(9):e46365.

10. Chu AH, Moy FM. Association between physical activity and metabolic syndrome among Malay adults in a developing country, Malaysia. J Sci Med Sport 2014;17(2):195-200.

11. Narayanan P, Meng OL, Mahanim O. Do the prevalence and components of metabolic syndrome differ among different ethnic groups? A cross-sectional study among obese Malaysian adolescents. Metab Syndr Relat Disord 2011;9(5):389-95.

12. Ryo M, Nakamura $T$, Kihara S, Kumada M, Shibazaki S, Takahashi M, et al. Adiponectin as a biomarker of the metabolic syndrome. Circ J 2004;68(11):975-81.

13. Matsuzawa Y. Establishment of a concept of visceral fat syndrome and discovery of adiponectin. Proc Jpn Acad Ser B Phys Biol Sci 2010;86(2):131-41.

14. Renaldi O, Pramono B, Sinorita H, Purnomo LB, Asdie RH, Asdie AH. Hypoadiponectinemia: a risk factor for metabolic syndrome. Acta Med Indones 2009;41(1):20-4. 
15. Wong GW, Wang J, Hug C, Tsao TS, Lodish HF. A family of Acrp30/adiponectin structural and functional paralogs. Proc Natl Acad Sci U S A 2004;101(28):10302-7.

16. Comuzzie AG, Funahashi T, Sonnenberg G, Martin LJ, Jacob HJ, Black AE, et al. The genetic basis of plasma variation in adiponectin, a global endophenotype for obesity and the metabolic syndrome. J Clin Endocrinol Metab 2001;86(9):43215.

17. Leech NL, Barret KC, Morgan GA. Chapter 8: Factorial ANOVA and ANCOVA. In: SPSS for Intermediate Statistics: Use and Interpretation. 5th edition. New Jersey: Lawrence Erlbaum Associates; 2005. p. 188-212.

18. Koh SB, Park JK, Yoon JH, Chang SJ, Oh SS, Kim JY, et al. Preliminary report: a serious link between adiponectin levels and metabolic syndrome in a Korean nondiabetic population. Metabolism 2010;59(3):333-7.

19. Onat A, Hergenc G, Can G, Kucukdurmaz Z. Serum adiponectin confers little protection against diabetes and hypertension in Turkish men. Obesity (Silver Spring) 2009;17(3):564-70.

20. Kazumi T, Kawaguchi A, Hirano T, Yoshino G. Serum adiponectin is associated with high-density lipoprotein cholesterol, triglycerides, and low-density lipoprotein particle size in young healthy men. Metabolism 2004;53(5):589-93.

21. King GA, Deemer SE, Thompson DL. Adiponectin is associated with risk of the metabolic syndrome and insulin resistance in women. Acta Diabetol 2012;49 Suppl 1:S41-9.

22. Huang MC, Wang TN, Lee KT, Wu YJ, Tu HP, Liu CS, et al. Adiponectin gene SNP276 variants and central obesity confer risks for hyperglycemia in indigenous Taiwanese. Kaohsiung $J$ Med Sci 2010;26(5):227-36.

23. Specchia C, Scott K, Fortina P, Devoto M, Falkner B. Association of a polymorphic variant of the adiponectin gene with insulin resistance in african americans. Clin Transl Sci 2008;1(3):194-9.

24. Gavrila A, Chan JL, Yiannakouris N, Kontogianni M, Miller LC, Orlova C, et al. Serum adiponectin levels are inversely associated with overall and central fat distribution but are not directly regulated by acute fasting or leptin administration in humans: cross-sectional and interventional studies. $J$ Clin Endocrinol Metab 2003;88(10):4823-31.

25. Yamamoto $Y$, Hirose H, Saito I, Tomita M, Taniyama M, Matsubara K, et al. Correlation of the adipocyte-derived protein adiponectin with insulin resistance index and serum high-density lipoprotein-cholesterol, independent of body mass index, in the Japanese population. Clin Sci (Lond) 2002;103(2):137-42.

26. Laughlin GA, Barrett-Connor E, May S, Langenberg C. Association of adiponectin with coronary heart disease and mortality: the Rancho Bernardo study. Am J Epidemiol 2007;165(2):164-74.

27. Rathmann W, Haastert B, Herder C, Hauner H, Koenig W, Meisinger $\mathrm{C}$, et al. Differential association of adiponectin with cardiovascular risk markers in men and women? The KORA survey 2000. Int J Obes (Lond) 2007;31(5):770-6.

28. von Eynatten M, Schneider JG. The role of adiponectin in atherosclerosis: do lipids tip the scales? Future Cardiol 2005;1(6):775-84.

29. Staiger H, Tschritter O, Machann J, Thamer C, Fritsche A, Maerker E, et al. Relationship of serum adiponectin and leptin concentrations with body fat distribution in humans. Obes Res 2003;11(3):368-72.

30. Seino Y, Hirose H, Saito I, Itoh H. High-molecular-weight adiponectin is a predictor of progression to metabolic syndrome: a population-based 6-year follow-up study in Japanese men. Metabolism 2009;58(3):355-60.

31. Ninghayu C, Wijaya A, As'ad S. Association between multimeric adiponectin and free leptin index with atherogenic dyslipidemia in non-diabetic obese men. Medical Journal of Indonesia 2011;20(2):119-23.

32. Lara-Castro C, Luo N, Wallace P, Klein RL, Garvey WT. Adiponectin multimeric complexes and the metabolic syndrome trait cluster. Diabetes 2006;55(1):249-59.

33. Hanley AJ, Bowden D, Wagenknecht LE, Balasubramanyam A, Langfeld C, Saad MF, et al. Associations of adiponectin with body fat distribution and insulin sensitivity in nondiabetic Hispanics and African-Americans. J Clin Endocrinol Metab 2007;92(7):2665-71.

34. Furuhashi M, Ura N, Higashiura K, Murakami H, Tanaka M, Moniwa $\mathrm{N}$, et al. Blockade of the renin-angiotensin system increases adiponectin concentrations in patients with essential hypertension. Hypertension 2003;42(1):76-81.

35. Francischetti EA, Celoria BM, Duarte SF, da Silva EG, Santos IJ, Cabello PH, et al. Hypoadiponectinemia is associated with blood pressure increase in obese insulin-resistant individuals. Metabolism 2007;56(11):1464-9.

36. Hotta K, Funahashi T, Arita Y, Takahashi M, Matsuda M, Okamoto Y, et al. Plasma concentrations of a novel, adiposespecific protein, adiponectin, in type 2 diabetic patients. Arterioscler Thromb Vasc Biol 2000;20(6):1595-9.

37. Tschritter O, Fritsche A, Thamer C, Haap M, Shirkavand F, Rahe $\mathrm{S}$, et al. Plasma adiponectin concentrations predict insulin sensitivity of both glucose and lipid metabolism. Diabetes 2003;52(2):239-43.

38. Daimon M, Oizumi T, Saitoh $\mathrm{T}$, Kameda $\mathrm{W}$, Hirata A, Yamaguchi $\mathrm{H}$, et al. Decreased serum levels of adiponectin are a risk factor for the progression to type 2 diabetes in the Japanese Population: the Funagata study. Diabetes Care 2003;26(7):2015-20.

39. Spranger J, Kroke A, Mohlig M, Bergmann MM, Ristow M, Boeing $\mathrm{H}$, et al. Adiponectin and protection against type 2 diabetes mellitus. Lancet 2003;361(9353):226-8.

40. Vendramini MF, Pereira AC, Ferreira SR, Kasamatsu TS, Moises RS. Association of genetic variants in the adiponectin encoding gene (ADIPOQ) with type 2 diabetes in Japanese Brazilians. J Diabetes Complications 2010;24(2):115-20.

41. Zhu W, Cheng KK, Vanhoutte PM, Lam KS, Xu A. Vascular effects of adiponectin: molecular mechanisms and potential therapeutic intervention. Clin Sci (Lond) 2008;114(5):361-74. 